Artículos Resultado de la Investigación

\title{
Responsabilidad de empresarios ante la Corte Penal Internacional
}

\section{Employers liability to the international criminal court}

\section{Empregadores responsabilidade do tribunal penal internacional}

\author{
Yenifer Yiseth Suárez Díaz ${ }^{1}$ \\ ${ }^{1}$ Universidad Nacional de Colombia, Obervatorio de Política Criminal, Colombia
}

\begin{abstract}
Resumen
El constante cambio de las dinámicas sociales, propiciado por el desarrollo económico y tecnológico, ha traído consigo la necesidad de disponer de un alto tribunal que conozca de los delitos de carácter internacional, para lo cual se estableció la Corte Penal Internacional, destinada a perseguir y condenar a los máximos responsables de los delitos de su competencia. No obstante, y pese al establecimiento de responsabilidad en calidad cómplice a aquellos empresarios que contribuyen con las conductas punibles, no existe investigación ni condena en tal tribunal, por lo que a partir de un estudio criminológico se evalúa el actuar político criminal realizado por el derecho penal internacional en el establecimiento de responsabilidad a empresarios por crímenes de su competencia, a partir de las categorías dogmáticas establecidas en las directrices internacionales y en la doctrina internacional.
\end{abstract}

Palabras clave: Derecho penal, derecho internacional, criminología, derechos humanos, política pública

\begin{abstract}
The constant changes in the social dynamics due to economic and technological development has brought along the need to dispose of a High Court, with competence over International Crimes. The above was the reason to establish the International Criminal Court, destined to prosecute and punish the maximum responsible for crimes of its jurisdiction. Nonetheless, despite the existence of individual criminal responsibility as an accomplice in the case of entrepreneurs who contribute to the crime, there is not an actual investigation or conviction as such in the Court fase for those individuals. Through a criminological study, the actions in the frame of the criminal policy in international law, in order to hold individual criminal responsibility towards entrepreneurs for international crimes, will be evaluated, from the dogmatic categories established in the international guidelines as well as from international doctrine.
\end{abstract}

Key words: Criminal Law, International Law, criminology, Humans Rights, policy maker

\begin{abstract}
Resumo
As constantes mudançasnadinâmica social, devidoaodesenvolvimentoeconômico e tecnológico temtrazido a necessidade de dispor de um Tribunal Superior, comcompetência sobre CrimesInternacionais. 0 texto acimafoi a razão para o estabelecimento do Tribunal Penal Internacional, destinado a processar e punir o máximo responsável por crimes de suajurisdição. No entanto, apesar da existência de responsabilidade criminal individual como cúmplice no caso de empresários que contribuem para o crime, nãoháumainvestigação real ouconvicção como tal na fase Tribunal para aquelesindivíduos. Através de umestudo criminológico, as ações no quadro da política criminal emdireito internacional, a fim de manter a responsabilidade criminal individual para empresários por crimesinternacionais, serãoavaliados, a partir das categorias dogmáticas estabelecidas pelos padrõesinternacionais, bem como da doutrina internacional.
\end{abstract}

Palavras-chave: Direito Penal, Direito Internacional, criminologia, os humanos direitos, máquina política

Correspondencia: Yenifer Yiseth Suárez Díaz. Universidad Nacional de Colombia. revistalogos@policia.edu.co 


\section{Introducción}

Las dinámicas en las que el mundo se desarrolla a partir de la globalización como fenómeno económico, político, social y jurídico, han impuesto formas de desarrollo en la comunidad para enfrentarse a los males que tales dinámicas imponen; se ha transformado el Estado-Nación, con límites claramente establecidos, no solo geográficos sino normativos, en la construcción de una sociedad global en la que las fronteras desaparecen, y ello inevitablemente ha implicado transformaciones en todos los ámbitos de la sociedad; en el campo jurídico, la norma ha dejado de poseer un carácter territorial y temporal delimitado para adoptar los cánones de una situación crónica y de emergencia(Agamben, 2004 en Iglesias Skulj \& Vargas Ovalle, 2009), presentando el atractivo del imperio como etapa para la justicia global (Morrison, 2009, p. 37).

Así, fundamentándose en la trascendencia de las acciones que más conmueven la conciencia de la humanidad y las que se consideran de mayor gravedad, se parte de los genocidios ocurridos durante la segunda guerra mundial, en Ruanda y la antigua Yugoslavia para la creación de la Corte Penal Internacional, como órgano supremo capaz de enfrentar las nuevas formas de criminalidad capaces de vulnerar la paz, la seguridad y el bienestar mundial.

Lo anterior implica que, ante un nuevo modelo de justicia global, se imponga una nueva estrategia de política criminal en la que se hace necesario transformar la evaluación de la individualidad y personalidad del sujeto en la evaluación del riesgo criminal de determinados grupos criminales (Ciappi, 2010, p. 33), en la que su persecución se basa en la pertenencia a una organización capaz de llevar a cabo acciones criminales como los delitos de lesa humanidad; así, de un lado se observa que los delitos dejan de ser cometidos por sujetos aislados y que su perpetración se hace desde una organización, que no debe ser evaluada únicamente desde la Convención de Palermo, sino que revisten tal magnitud que recaen en la competencia de la Corte Penal Internacional.

De esta manera, la política criminal propone, de un lado, la transformación y redefinición de los bienes jurídicos, debido a la propagación de políticas penales neoliberales que han hecho de las cuestiones de seguridad uno de los pilares de muchas arquitecturas penales (Ciappi, 2010, p. 31 ), y de otra parte, la formulación de una nueva responsabilidad para los individuos que cometen acciones delictivas descritas en el Estatuto de Roma enfocándose en el ataque a la organización criminal, basado en el riesgo social y especialmente en la reacción social. La selectividad del sujeto responsable penalmente en el ámbito internacional pasa de la evaluación de la individualidad y personalidad del sujeto a la evaluación del riesgo criminal de determinados grupos (Ciappi, 2010, p. 33), su persecución se basa en la pertenencia a una organización capaz de llevar a cabo acciones criminales como los delitos de lesa humanidad.

Para justificar la persecución de un individuo debido a su pertenencia a un grupo o una organización, se parte de la concepción del Tribunal Penal Internacional como máxima instancia jurisdiccional, encargada únicamente de perseguir y sancionar los delitos de mayor gravedad para la humanidad y sus pepetradores, pero únicamente los que son considerados máximos responsables, es decir, quienes coordinan, lideran o contribuyen a la organización criminal.

A fin de establecer legalmente la responsabilidad de los agentes pertenecientes a una organización con poder económico y que contribuyen a través de la financiación a los delitos consagrados en el Estatuto de Roma, se ha entendido la modalidad de participación por el informe de la Comisión Internacional de Juristas como la complicidad empresarial (Comisión Internacional de Juristas, 2010), ello quedó plasmado en el artículo 25 del Estatuto de Roma, en el que se señala la colaboración con un crimen cometido por un grupo con un propósito común, y que ha sido desarrollado por diversas decisiones del tribunal penal internacional (Fiscalía vs. William Samoeiruto, Henry KipronoKosgey and Joshua Arap Sang, 2012), (Fiscalía vs. Callixte Mbarushimana, 2011); esto ha provocado en el ámbito global una extensa preocupación por la ponderación entre el desarrollo económico de diversas empresas y la protección de derechos humanos, lo que llevó finalmente al establecimiento por parte de la Organización de Naciones Unidas de los Principios Rectores sobre las empresas y los derechos humanos ${ }^{1}$

Tal desarrollo implica un necesario cambio en la concepción de criminalidad internacional, toda vez que existe un interés de la comunidad internacional de buscar salidas globales a algunos de los problemas que hacen que haya una orientación de política criminal también 
global (Ibañez, 2001), se adopta como criterio criminal, la pertenencia del sujeto a aquellas organizaciones que pudiesen cometer delitos transnacionales o colaborar en su comisión, aún más cuando se parte de la exigibilidad de una conducta a partir del rol requerido por la sociedad en relación con su función empresarial; se produce, entonces, además de la redefinición de bienes jurídicos, la búsqueda de la justicia, la protección de las víctimas ante la organización criminal y se constituyen en las bases de una política criminal circunstancial, generada por la globalización del mundo actual.

La política criminal, que en principio se encuentra en cabeza del estado, encuentra una disminución en su poder, a raíz del proceso de globalización que conlleva a:

“(...)la erosión progresiva de la capacidad estatal del ejercicio de la fuerza, la cualidad fundamental que definía el contenido de la soberanía de la acción política estatal, lo que transforma la visión moderna de la política, la violencia y los métodos de resolución de los conflictos". (Córdoba E, p. 27)

Sin embargo a partir de la concepción de nuevos bienes jurídicos tales como la seguridad, algunos autores determinan que en la actualidad:

"El sistema penal, y la política criminal instituida, son selectivos, ello implica que sus enfrentamos a la criminalidad organizada que se vale de esos marginales para realizar sus operaciones pero sus destinatarios son los marginales, los excluidos esto es aún más complejo cuando que en la cúpula tienen dirigentes poderosos, tanto en el plano político como económico." (Contreras López, p. 10)

El sistema penal reviste un carácter selectivo, en el que la pena se encuentra dirigida entonces, a aquellos que la sociedad ha dejado como marginados y que no pueden adaptarse a los procesos económicos que sufre la masa social, ejemplo de ello se observa en Francia donde aumentan las protestas por la "destrucción del empleo", en las cuales, un líder sindical señala: “ Con tantos trabajadores en la calle creo que no podrán quedarse al margen"(Elespectador.com, 2012), efectivamente tales sujetos serán potenciales peligros para la comunidad que aún conserva su trabajo y por ello, el mecanismo mediante el cual no quedarán al margen será su señalamiento y posterior castigo penal, por ser un factor de riesgo.
Tal crisis del derecho penal garantista, culmina en un proceso de formalización jurídica, de consagración de bienes y tipos penales colectivos en códigos nacionales o estatutos universales, meramente formales ya que la política criminal no pierde su carácter selectivo sobre los sujetos que se han denominado marginales de la sociedad, y únicamente se someten a los procesos penales a tales individuos y no a aquellos que atentan contra los intereses construidos desde posiciones sociales, económicas y políticas privilegiadas, en palabras de Ferrajoli (2013) hay un derecho penal máximo para los individuos que cometen delitos locales y un derecho penal mínimo para quienes cometen delitos de masa.

Por lo cual, en el medio globalizado, no solo ha intervenido el mercado como factor de creación de bienes jurídicos, sino que han confluido la criminología actuarial, como mecanismos políticos, económicos y electorales en la sociedad, para definir discursivamente aquellos intereses que se encuentran potencialmente en riesgo, en contraposición al bien jurídico intermedio de la seguridad.

Frente a la responsabilidad empresarial se han desarrollado investigaciones dirigidas a las infracciones que causan, atendiéndolas como daño para dar lugar a la responsabilidad administrativa o civil. En el campo del derecho penal, la discusión se ha centrado en la posible responsabilidad de las personas jurídicas, o como indica Cesano:

"La combinación de los diversos problemas reseñados ha conducido a que, desde una perspectiva político-criminal, se hayan elaborado distintas respuestas para abordar la criminalidad sucedida en el ámbito empresarial, propuestas que van desde soluciones intermedias que, negando la posibilidad de responsabilizar penalmente a los entes ideales, postulan, ora su punibilidad a título contravencional (con lo cual se traslada el problema del ámbito del derecho criminal al del derecho penal administrativo), ora la utilización -a su respecto- de medidas de seguridad, hasta el surgimiento de una fuerte corriente de opinión que propugna, directamente, la consagración de un doble sistema de imputación".(Cesano, 2009, p. 349)

Atendiendo al papel influyente que desempeñan las empresas dentro del nuevo orden económico, social y político y a la posible violación de derechos humanos se ha ido fortaleciendo la idea 
de la responsabilidad empresarial frente a esto, pero dentro del marco civil como responsabilidad de la persona jurídica, ante lo cual se han establecido mecanismos de seguimiento a su responsabilidad ética, tales como el Pacto Mundial (Global Compact, en inglés), propuesto por el Secretario de Naciones Unidas en el Foro Económico Mundial el 31 de enero de 1999, el cual corresponde a una iniciativa voluntaria de las empresas en la cual estas se comprometen a alinear sus estrategias y operaciones con diez principios universalmente aceptados, en cuatro áreas temáticas: derechos humanos, estándares laborales, medio ambiente y anticorrupción, para la construcción de la legitimación social de los negocios y los mercados. Con miles de empresas comprometidas en más de 100 países, el Pacto Mundial es la iniciativa de ciudadanía corporativa más grande.

Por ello, a pesar de que la Corte Penal Internacional se instituyó en el derecho internacional, a través de la firma del tratado multilateral de Estatuto de Roma, como el mecanismo de protección penal mediante el cual se persigue a los máximos responsables de conductas punibles de competencia del Tribunal Internacional, estableciendo la sanción en contra de aquellos que contribuyan de algún modo en la comisión de crímenes de competencia de la CPI como parte de una organización criminal, tal persecución no se ha llevado a cabo en contra de los dirigentes empresariales que participan en la comisión de crímenes internacionales como parte de una organización. Lo anterior devela el uso de una política criminal internacional actuarial y selectiva a través de la cual se protegen las conductas corporativas que favorecen los delitos de carácter internacional.

\footnotetext{
${ }^{1}$ El Ilamado Informe Ruggie, "Principios Rectores sobre las empresas y los derechos humanos: puesta en práctica del marco de las Naciones Unidas para "proteger, respetar y remediar" fue respaldado el 16 de junio de 2011 por el Consejo de Derechos Humanos de Naciones Unidas.
}

\section{Metodología empleada}

Para arribar a la anterior conclusión y considerando que la investigación depende de la calidad y cantidad de información que se pueda recolectar (Giraldo Ángel, 2010, p. 133), ya que serán los insumos mediante los cuales se analizarán las diferentes variables, la recolección de la información se realizó mediante el análisis de documentos, a partir de datos que reposan en archivos oficiales o privados (Giraldo Ángel, 2010, p. 141), tomando documentos oficiales expedidos por la Corte Penal Internacional, y la doctrina existente acerca de la responsabilidad empresarial, entendida a partir del fenómeno de complicidad, bajo el artículo 25, numeral 3, literal $\mathrm{d}$; tales como los realizados desde la doctrina del derecho Internacional y por ONG e Instituciones que han contribuido al fortalecimiento del derecho Penal Internacional.

Debe advertirse que por tratarse de un tribunal relativamente nuevo y el cual solo ha expedido tres sentencias dentro de su jurisprudencia, se consideraron las decisiones tomadas por el tribunal internacional dentro de los procesos penales llevados a cabo y que aún no culminan, así como las decisiones judiciales que han contribuido en el desarrollo dogmático respecto de la complicidad empresarial.

Sobre la información obtenida se llevó a cabo un análisis cualitativo, a través del cual se seleccionó la información útil en relación al problema de investigación, efectuando un proceso de operacionalización a partir de las variables planteadas en el problema de investigación.

Entendiendo por operacionalización el resultado de un proceso a través del cual se explica en detalle los tipos de valores que pueden tomar las variables (cuali o cuantitativas) y los cálculos realizados para obtener los indicadores de esas variables (Scharager, 2001), teniendo en cuenta que la definición conceptual, fuera coherente con la definición operacional en función de la hipótesis y el problema que se pretende desarrollar, las variables operacionalizadas fueron: máximos responsables, organización criminal, crímenes internacionales, política criminal y conductas corporativas.

Frente al uso del método en el derecho internacional, se han planteado críticas, bajo las cuales, en principio, el método en derecho internacional es una investigación paciente y cuidadosa dotada de rigor, que trae como resultado una mayor certeza y objetividad(Pinto Basto Lupi, 2010, p. 13), sin embargo, se ha indicado que no se puede pretender el reducir la investigación a conceptos determinados, en tanto la indeterminación forma parte de la estructura de la argumentación internacional (Pinto Basto Lupi, 2010, p. 14), lo cual puede ser reparado mediante estrategias argumentativas.

Por lo cual, conforme a las variables a 
operacionalizar, se debe señalar que, de acuerdo a lo mencionado, frente a la variable máximos responsables, y la inexistencia de criterios unificados en derecho internacional, se hizo necesario acudir al derecho comparado como método de interpretación, en tanto este tiene el más ambicioso objetivo de preparar un acercamiento internacional del derecho (Zweigert, 1958, p. 58); la comparación fue necesaria para que un tratado internacional sea interpretado y aplicado por cada país, conforme a los objetivos planteados, creando la exigibilidad de un tratamiento uniforme en los países miembro.

Para poder realizar el análisis a partir del derecho comparado se eligieron únicamente zonas jurídicas que por su naturaleza sean de índole internacional (Zweigert, 1958, p. 59), en este caso el derecho penal internacional, tendiente a la protección de derechos humanos, los cuales no requieren un único método, sino que exigen una pluralidad de métodos (Häberle, 1992, p. 916).

Frente al análisis de la política criminal, se llevó a cabo un estudio, en el cual se consideró esta como política pública, teniendo en cuenta que para ello se han planteado diversas técnicas, sin existir una única metodología, por lo que se tendrá en cuenta en primer lugar la agendación, formulación e implementación, valorando que esta cuente con los elementos requeridos para ser una política pública y conforme a ello, determinar su existencia o no, realizar un análisis de actores, considerando que todo individuo o grupo social vinculado con el problema colectivo que origina la política pública debe considerarse actor potencial del "espacio" de la mencionada política (Knopfel, 2007, p. 9), valorando los elementos con los que cuenta cada actor y su capacidad estratégica en la formulación de la política.

Seguidamente, se abordaron los enfoques de dicha política pública a partir de la racionalidad limitada, ello es la teoría de la elección racional y del publicchoice, bajo una fuerte dimensión normativa, en la cual la mayor eficiencia en las políticas públicas se obtiene guiando o incentivando correctamente a través de las instituciones adecuadas, los comportamientos racionales y egoístas de los actores individuales y colectivos (Roth Deubel, 2007, p. 70), se señalaron las posibles alternativas en materia de política criminal internacional y se eligieron las que se encuentren en concordancia con el problema jurídico.

En ese orden, se analizaron las conductas corporativas desde la criminología de los delitos de cuello blanco, la cual en primer lugar pone de relieve que sujetos pertenecientes a un status económico elevado cometen acciones delictivas y señala algunas razones por las cuales tales delitos no son perseguidos o investigados. Un estudio desarrollado por Shuterland se limita a los delitos económicos, pero el presente trabajo tiene un mayor alcance pues se dirige a las violaciones graves de derechos humanos, observando el desarrollo que en derecho penal internacional han tenido estas conductas, hasta la interpretación que se brinda en la actualidad al artículo 25(3)(d) del Estatuto de Roma, y ha encontrado que, efectivamente, desde la legalidad existe un mecanismo para condenar las conductas que contribuyen a los crímenes de competencia de la Corte Penal Internacional, entre las cuales se pude incluir la financiación de parte de los poderes económicos, pero que no son el objeto de investigación de la criminología, porque el Tribunal Penal obedece a criterios de la criminología actuarial seleccionando situaciones en países en desarrollo, perfilando sujetos criminales, propagando la segregación y organizando desde la nueva geografía las condiciones jurídicas de la mal llamada integración.

Por lo que al final se hace una pequeña reflexión en torno a la respuesta que podría darse desde la criminología con un enfoque desde los derechos humanos y a través de la cual se conviertan en objeto de estudio las conductas criminales a gran escala, los que producen mayores víctimas que los delitos de las zonas urbanas a las cuales se ha dirigido la criminología actuarial.

\section{Política Criminal Internacional como Política Pública}

El concepto de política criminal como estándar previamente establecido, surge con la Escuela de Política Criminal de Franz Von Liszt la cual se ocupaba de la delincuencia en particular y de que la pena se adaptase en su especie y medida al delincuente, procurando impedir la comisión de crímenes en el futuro. Bustos Ramírez la precisa como el poder para definir los procesos criminales dentro de la sociedad y por ello mismo el poder para dirigir y organizar el sistema social en relación a la cuestión criminal(Bustos Ramírez, 1996), el Diccionario Jurídico la define como el conjunto de criterios 
mantenidos por el legislador para determinar qué conductas deben calificarse como delitos y qué penas deben asignárseles a aquellos, importa destacar pues que es cuestión de filosofía jurídica de la mayor trascendencia (Fundación Tomás Moro, 1999, p. 764).

En Colombia ha sido definida por la Corte Constitucional, en la sentencia C-936-10 como:

"El conjunto de respuestas que un estado estima necesario adoptar para hacer frente a conductas consideradas reprochables o causantes de perjuicios sociales con el fin de garantizar intereses esenciales del estado y derechos de los residentes en el territorio bajo su jurisdicción"

Así, la política criminal debe ser observada como realidad operativa y actuante en el derecho positivo (Sanchís, 2003, p. 21 ), que a la postre resulta en la implementación de una política pública que contenga una perspectiva integral de la criminalidad para el establecimiento de criterios uniformes mediante los cuales se establezca una estrategia común frente a los delitos y que garantice la protección de Derechos Humanos.

Por lo que la política criminal como política pública es la reacción de carácter estatal o en este caso internacional, mediante la cual los organismos e instrumentos internacionales valoran un hecho como delictivo y en consecuencia a quien participa en su comisión se clasifica en la categoría de delincuente, la política pública en materia criminal comprende tanto los discursos como objetivos de todos los operadores institucionales y la sociedad civil organizada a quienes incumbe el fenómeno delictual (Juárez Bribiesca \& Medina Ramírez P. 164)

\section{Actores de la Política Criminal Internacional}

Para analizar la política criminal como política pública, se describieron los participantes en su formulación e implementación, su participación e importancia en dicho proceso, en primer lugar se tuvo en cuenta a la Organización de Naciones Unidas y su labor desde sus diversas dependencias en la creación de la Corte Penal Internacional y la redacción del Estatuto de Roma.

Dentro de la formulación de la política se encuentra la Coalición de ONG que tuvo como objetivo la creación de una Corte Penal Internacional eficaz y justa. La Coalición reunió una amplia red de expertos en derecho internacional para elaborar estrategias sobre asuntos específicos legales y políticos relacionados con la puesta en marcha de la CPI. Un objetivo importante es promover la comprensión y el respaldo de un amplio sector de organizaciones civiles tales como defensores de los derechos humanos, especialistas en derecho internacional, organizaciones humanitarias, religiosas, para la paz, de mujeres, y otras.

\section{Enfoque de la política criminal.}

Partiendo del concepto de política pública como una construcción discursiva hecha de argumentos y de elementos retóricos (Roth Deubel, 2007), este requiere un marco de análisis que permita su explicación o su construcción en caso de que la misma no exista; para ello en el análisis de la política criminal internacional, se partirá del estudio de la teoría de la elección o publicchoice, bajo el cual se entiende la política bajo un problema de acción colectiva, como señala Roth.

A la luz de esta perspectiva, debe realizarse un estudio económico referente al estudio de costo-beneficio, tomando dos o más teorías y determinando aquella que tenga mayor eficiencia, la cual se consigue guiando o incentivando correctamente los comportamientos racionales y egoístas de los actores individuales y colectivos(Roth Deubel, 2007, p. 70).

Frente a este punto se observa que existen dos posibles elecciones, por un lado la responsabilidad administrativa frente a las personas jurídicas, y por otro lado la responsabilidad penal individual; algunos países han adoptado la responsabilidad administrativa, sin embargo tratándose de un derecho penal de carácter internacional y en el cual se consagra la responsabilidad individual, no debería tener tales diferenciaciones sino que debería estructurarse bajo una misma lógica. Tal responsabilidad desde la política criminal debe, además, contar con un enfoque de protección de derechos humanos, entendidos como el eslabón que se asocia indivisiblemente a la nueva criminología y a las nuevas teorías del proceso penal (Aniyar, 2010, p. 
57), adscribiéndose a la corriente a la cual se dirigen en la actualidad los criminólogos críticos para la investigación y persecución de los delitos que generan violaciones a los derechos humanos.

\section{Criterios para la definición de máximos responsables}

\section{Derecho comparado como método de interpretación.}

La normatividad hace parte del denominado pluralismo jurídico de Savigny, bajo los cuales se crean mecanismos de integración bien sea regional o universalmente, articulando bien será relaciones económicas u obligaciones en el campo de los derechos humanos.

Por lo cual frente a la variable máximos responsables, y la inexistencia de criterios unificados en derecho internacional, se acudió al Derecho Comparado como método de interpretación, en tanto este tenga el más ambicioso objetivo de preparar un acercamiento internacional del Derecho (Zweigert, 1958, p. 58 ), siendo la comparación necesaria para que un tratado internacional sea interpretado y aplicado por cada país, conforme a los objetivos planteados, creando la exigibilidad de un tratamiento uniforme en los país miembro.

Para poder realizar el análisis a partir del derecho comparado deben escogerse únicamente zonas jurídicas que por su naturaleza sean de índole internacional (Zweigert, 1958, p. 59), en este caso el derecho penal internacional, tendiente a la protección de derechos humanos, los cuales no requieren un único método, sino que exigen una pluralidad de métodos (Häberle, 1992, p. 916).

Si bien, conforme al artículo 93 de la Constitución Política y de acuerdo a lo establecido en la sentencia C-591-05 de la Corte Constitucional, el Estatuto de Roma, hace parte del derecho interno, no se pretendió llevar a cabo un estudio de la normatividad internacional comparada con la legislación nacional, sino analizar las diversas interpretaciones que se han llevado a cabo por diversos países frente a la expresión máximos responsables, a fin de establecer aquellos criterios de valoración y selección de sujetos a llevar ante la Corte Penal Internacional, igualmente dicho estudio se realizó vinculándolo a la interpretación dada frente a los dirigentes empresariales en la comisión de crímenes de carácter internacional.
Por lo que frente a la dificultad de interpretación sintáctica de frases adjetivales, la duda de si los adjetivos y las frases adjetivales califican dos 0 más palabras, (Ross, 1997), en este caso lo que se ha señalado como máximos responsables o mostseniorleaders, aun cuando dentro de la doctrina comparatista se ha indicado su utilización para problemas teóricos en la creación del texto jurídico o la decisión judicial o en la comprensión de un texto legal, se considera de especial importancia el establecimiento de criterios que permitan determinar los sujetos a ser perseguidos por la fiscalía de la Corte Penal Internacional en tanto, no solo ello comporta una garantía para la sociedad en general sino que establece garantías procesales para los acusados.

El término máximos responsables o seniorleaders, surgió en el Tribunal Especial para Sierra Leona y que se asumió como parte de la estrategia de la fiscalía (Conferencia de Revisión Kampala, 2010, Anexo V.c. p.1211), sin embargo no se encuentra determinado legalmente por el Estatuto de Roma o existen criterios claramente estipulados que permitan determinar qué sujeto se trata de un máximo responsable, no obstante, debido al carácter masivo de los crímenes y puesto que la Corte es el tribunal de última instancia, aplica una política de enjuiciar solo a aquellos en quienes recae la mayor parte de la responsabilidad (Conferencia de Revisión Kampala, 2010, Anexo V.a. p. 95).

Y si la Corte se va a ocupar en principio de los máximos responsables de delitos masivos tendrá frecuentemente ante sí casos en los que esos máximos responsables no habrán ejecutado de propia mano los elementos del tipo penal. En este contexto, es crucial desarrollar herramientas interpretativas para determinar cuál es la conducta, cuáles son las circunstancias y, lo más importante, qué sucesos pueden comprenderse como consecuencias de la conducta (Kiss, 2013, p. 7)

Al respecto se revisó la responsabilidad a empresarios en Alemania, en donde se dirigió al ataque en contra de la corrupción; en Argentina, donde se conoció la reciente sentencia en contra de Pedro Blaquier por las actuaciones adelantadas como dueño del Grupo Ledesma, ingenio azucarero durante la dictadura argentina, como responsable de los secuestros, desapariciones y torturas ocurridas en la noche del apagón, en el mismo fallo se determinó la participación de Blaquier como cómplice necesario, en la comisión de crímenes calificados 
de lesa humanidad en el marco de un ataque generalizado y sistemático, aplicando las normas vigentes al momento de la comisión de los crímenes ello es el derecho penal consuetudinario, y a partir de un estudio de derecho internacional y derecho comparado en la interpretación de la participación y autoría en un crimen internacional, determina la modalidad de participación a través de una contribución sustancial, es decir que tenga un efecto en la comisión (Burgos, Luis y otros, 2012).

Luego de analizar la responsabilidad en España, Francia, Costa de Marfil, Perú, Colombia y Bolivia enfocada a la condena de las personas jurídicas que vulneraban la legislación vigente, se determinaron como criterios para el establecimiento de máximos responsables, lo desarrollado en Inglaterra y Estados Unidos, que se han constituido como criterios orgánicos, jerárquicos y funcionales, por lo que esos últimos se consideraron los aplicables para llevar a un individuo ante la Corte Penal Internacional.

Resulta este, el criterio más importante en la determinación de un sujeto responsable, ya que más que observarse el cargo que ocupa el individuo dentro de la Corporación es la valoración que debe realizarse en un doble sentido:

Por un lado, debe evaluarse el crimen cometido y la cadena causal para su comisión, lo que no implica llegar a una cadena causal infinita, por lo que se debe observar la contribución de la persona en el acto criminal y la significación de este.

Una vez realizado ello, se debe observar si la contribución se hizo con ocasión de la pertenencia a una empresa, en ese sentido se debe apreciar su capacidad estratégica.

\section{Criminología de los delitos de cuello blanco}

Teniendo en cuenta los desarrollos sociales, tecnológicos, económicos y culturales, así como del derecho penal, la criminalidad y el delincuente deben tener un estudio, bajo el cual no se tenga como referencia el castigo o la rehabilitación de individuos sino la identificación y el manejo de grupos difíciles de controlar( Fuente especificada no válida. ), atendiendo al doble discurso que se efectúa desde el derecho penal que, de acuerdo a lo señalado por ÁlvarezUría, por un lado penaliza los delitos de los pobres y de otro es complaciente y condescendiente con los delitos de los ricos.

No puede negarse que desde el nacimiento del derecho penal moderno, el comportamiento de las clases sociales bajas ha constituido el objeto de estudio del derecho penal, sin embargo existe un cambio de tendencia que lo aproxima más y más hacia la clase media, inclinándose también a la clase media alta e incluso acercándose a la clase alta, constituyéndose el centro de la legislación y la persecución penal(Fuente especificada no válida.) por lo cual la investigación realizada a partir del estudio de Shuterland, cuestionándose la responsabilidad penal desde otra perspectiva, permite detectar las falencias de la justicia en el campo internacional y así mismo plantear diversas salidas que conlleven a una sociedad que desde su propia universalidad sea más justa en su aplicación y en su protección de derechos.

Así, se define al delincuente de cuello blanco como a una persona con elevado status socioeconómico que viola las leyes destinadas a regular sus actividades profesionales (Shuterland, 1999, p. 330), se indica de "sus actividades profesionales" con el fin de diferenciar aquellos infracciones comunes, que pueden ser cometidas indistintamente por sujetos de alto o bajo nivel socioeconómico, sin embargo se excluyen delitos de la clase social alta como la mayoría de asesinatos, adulterio, intoxicación, etc., ya que estos no son generalmente parte de sus procedimientos ocupacionales (Shuterland, 1999, p. 65), por lo cual no podrían analizarse los delitos de competencia de la Corte Penal Internacional, no obstante el estudio del comportamiento criminal desde la teoría del delito de cuello blanco en la actualidad no puede pasar por alto que los comportamientos en los cuales los dirigentes corporativos emplean sus instrumentos económicos para la comisión de crímenes favorecen tanto a la organización criminal como al grupo corporativo al cual pertenecen, impulsando sus objetivos y desarrollo económico, por lo que dentro de la investigación serán consideradas aquellas contribuciones que favorezcan delitos que atentan contra la conciencia de la humanidad y que se den en razón a la pertenencia a un grupo económico.

Al respecto se tiene que, en su mayoría, las conductas realizadas desde los poderes económicos no se encuentran reguladas, son habitualmente tratados mediante diferentes tipos de autoridades controladoras ('agencias 
reguladoras') y frecuentemente con diferentes tipos de leyes (administrativas o reguladoras); si en algún caso devienen sujetos de la fuerza legal, tienden a ser apartados del ámbito de la ley criminal, y procesados utilizando esquemas administrativos o informales antes que por una acusación penal. Aun cuando fueran sujeto de un proceso criminal formal, "los crímenes corporativos rara vez son vistos como crímenes 'reales'"( Tombs, 2013, p.276).

Adoptando la criminología del delito de cuello blanco como enfoque de la responsabilidad empresarial ante la Corte Penal Internacional, debe tenerse en cuenta que la criminalidad está en función de la organización criminal, es decir debe atenderse a que este tipo de responsabilidad se enmarca en el riesgo desde una perspectiva grupal, atendiendo a que la participación del sujeto estudiado se hace desde una colaboración o un aporte a la comisión del crimen y por tanto no versa sobre actos individuales sino organizacionales, explicados desde la asociación diferencial.

\section{Complicidad Empresarial}

La consideración de la responsabilidad de los grupos empresariales ha tenido un evidente desarrollo al tener en cuenta la influencia que tales organizaciones tienen hoy en todos los aspectos de la sociedad, sin embargo esta se ha limitado al establecimiento de la responsabilidad social que recae en las empresas en la protección de derechos humanos, incluyéndose la complicidad como categoría de responsabilidad, así de acuerdo al Principio 2 del Pacto Global se establece: "Las empresas deben asegurarse de que sus empresas no son cómplices en la vulneración de los derechos humanos", que conforme al Plan de Naciones Unidas para el Desarrollo (PNUD) puede manifestarse de tres maneras: complicidad directa, por beneficio indirecto o complicidad silenciada, entendiendo que en la primera situación existe conocimiento y se colabora con la vulneración de derechos humanos, en el segundo caso la empresa se beneficia de las acciones violatorias de derechos ejecutadas por un tercero y la tercera modalidad se presenta cuando existe una pasividad frente a normas que restringen el ejercicio de los derechos (Programa de las Naciones Unidas para el Desarrollo), no obstante, las anteriores limitaciones continúan siendo discutidas frente a la imputación de responsabilidad en calidad de cómplices.

La responsabilidad bajo el artículo 25(3)(d) ha sido empleada en diversos casos de la CPI; en el caso de Germain Katanga en la decisión de ruptura de cargos se modificó la calificación jurídica realizada por la Fiscalía, en la cual se le acusaba como coautor en la modalidad señalada por el artículo 25(3)(a), imputandose la responsabilidad de acuerdo a lo dispuesto en el artículo 25(3)(d) (Fiscalía vs. Germain Katanga y Mathieu Ngudjolo Chui, 2012), al considerar que el acusado conocía la intención delictiva del grupo y el aporte significativo que realizó se encontraba en la realización de los elementos objetivos del tipo en el ataque a la población de Bogoro, sin embargo en esta decisión no se realiza un análisis dogmático de la responsabilidad en calidad de cómplice, sino que se adoptan los elementos previamente señalados en casos anteriores por la Corte Penal.

El análisis de la responsabilidad en calidad de cómplice se presenta en el caso seguido contra Callixte Mbarushimana en la situación de la República Democrática del Congo, en el cual la modalidad de responsabilidad bajo la cual se le acusó era la señalada en el artículo 25(3)(d), por la campaña mediática que presuntamente adelantaba desde Europa alentando la comisión de crímenes, en dicho caso, se examinó la categoría dogmática, estableciéndose por la Sala de Cuestiones Preliminares I, que la responsabilidad bajo este artículo exige tres elementos objetivos y dos subjetivos (Fiscalía vs. Callixte Mbarushimana. Decisión sobre la confirmación de cargos, 2011, p. 269).

Los elementos objetivos son: (i) que se haya cometido o intentado cometer un delito de jurisdicción de la corte, (ii) que la comisión o tentativa haya sido llevada a cabo por un grupo de personas actuando con un propósito común y (iii) la contribución al crímen haya sido otra a las señalades en el artículo 25(3)(a) a (c).

Los elementos subjetivos son: (i) la contribución debe ser intencional y (ii) puede ser con el fin de facilitar la actividad criminal o el propósito del grupo o con el conocimiento de la intención del grupo de cometer el delito.

Este grado de participación ha sido ampliamente discutido por la doctrina, que a su vez ha determinado la diferencia entre la contribución en calidad de cómplice y la Empresa Criminal Conjunta, en el sentido de que la persona no es 
responsable por el delito que cometa el grupo sino por su participación y contribución al delito (Kiss, 2013, p. 10) que debe ser de carácter grave, en el sentido de que en gran parte de los crímenes en los cuales hay graves violaciones a los derechos humanos, suele ser de mayor gravedad la contribución económica, por ejemplo, que se realiza a una organización criminal o con actuaciones criminales, que la responsabilidad del sujeto que ejecuta el delito.

\section{Lo que no se ha perseguido.}

Bajo los anteriores presupuestos y atendiendo el alcance de la responsabilidad de un sujeto que contribuye de alguna manera a un grupo en la comisión de crímenes de mayor gravedad y que por ende se encuentran bajo la competencia de la $\mathrm{CPI}$, se entiende que el interés de atacar la criminalidad organizada no se encuentra limitada a los ejecutores sino a quienes favorecen las violaciones de derechos humanos; considerando las condiciones económicas que se presentan en la actualidad y el interés de los actores económicos en la expansión de sus mercados, se tiene que a través de sus conductas en múltiples ocasiones han generado mayores víctimas que ejércitos en el marco de un conflicto armado; por ejemplo han financiado grupos ilegales para cometer actos como desplazamiento forzado, ejecutan condiciones laborales que se enmarcan en el tipo de trabajos forzados que incluyen tratos crueles e inhumanos o han impuesto condiciones de vida que pueden ser tipificados como el delito de exterminio, consagrado en el Estatuto de Roma.

Frecuentemente las empresas transnacionales actúan en países donde los gobiernos están dispuestos a sacrificar la protección de derechos humanos y del medio ambiente, si esto puede hacer más atractivo a su país (Geneviève, 2009, p. 39), por lo que desempeñan un papel de gran importancia no solo en las decisiones económicas sino en las decisiones políticas de un estado, actuando con organizaciones represivas y definiendo las condiciones de vida de los habitantes de una nación, lo que complejiza la situación cuando existen violaciones de derechos humanos y dificulta la identificación y persecución cuando se realizan aportes a una organización criminal, pues en su mayoría suelen ser difusos, remontar las cadenas de responsabilidad y demostrar lazos de causalidad que requiere la cooperación de numerosos sectores y de variadas competencias a nivel local y a nivel internacional(Geneviève, 2009, p. 104).

\section{Conclusiones: ¿Por qué no se ha actuado?: Criminología del mundo globalizado}

A partir del fin de la guerra fría y el triunfo del capitalismo sobre el comunismo, las políticas económicas promulgaron los mecanismos de integración estatal como el medio que utilizaba el consenso plasmado en acuerdos bi o multilaterales que favorecerían las relaciones económicas, comerciales y de producción de los pactantes, inicialmente tales convenios se dieron en términos regionales y se han dirigido a la universalización de los mismos, igualmente, el desarrollo de la integración se ha esforzado porque las dinámicas de interacción entre los países, no versen únicamente sobre temas económicos sino culturales, políticos y sociales, es así como dentro de esta dinámica se encuentra la globalización de los valores, entendida como la extensión gradual de principios éticos comunes (CEPAL, 2002, p. 21) y reflejada en los tratados sobre derechos humanos, lo que ha convertido ql derecho internacional en un conjunto de reglas que están enlazadas por la persuasión moral más que por la imposición de alguna agencia del orden (Morrison, 2009, p. 41), empleando los mecanismos de identificación de la sociedad con la víctima y aplicando la victimagogia para la definición del enemigo y del delincuente.

Por lo que la justificación de los fenómenos de integración y universalización se han fundamentado en la cooperación internacional, primero porque obedece a la contradicción de los discursos conflictivos y que hasta la guerra fría habían dividido evidentemente al mundo, y por otro lado en tanto se pretendió disuadir que a través de la globalización existe un intercambio de experiencias y recursos entre países para alcanzar el bienestar humano a través del desarrollo económico y social sostenible (Centro de Integración, Cooperación y Desarrollo Internacional), es decir, se entiende como una colaboración que se efectúa entre los estados para tal fin, no obstante, el discurso así descrito no ha considerado los problemas que se presentan en cuanto a la distancia entre integración simbólica al mundo global y escasa capacidad de integración material, debido a las marcadas desigualdades existentes (CEPAL, 2002, p. 26).

Como consecuencia de ello, lo que se ha dado es 
un proceso de segregación, en tanto el mismo concepto ecológico de población dado por la RAE, se entiende como el conjunto de individuos de la misma especie que ocupan una misma área geográfica, es decir clasifica únicamente a aquellos que pertenezcan a una única especie, y que en los términos de la globalización es quienes hagan parte de un mismo espacio, aun cuando hagan parte de la especie humana, por lo que la lógica bajo la cual se describe la política es que esta se rige de acuerdo al espacio dentro del cual se promueve, obligando al consenso para evitar la segregación o la muerte social. En términos de biopolítica, es un requerimiento hacerlo, pues como indica AGAMBEN: "Ios hombres están condenados, por así decirlo, a ponerse de acuerdo sobre los criterios de sentido y de validez de su acuerdo".

Surge entonces la criminología actuarial, que adopta una concepción económica del delincuente, en el sentido de que este es un sujeto racional que valora los costos y beneficios de su actuación (Sozzo, 2000, p. 55, 56), convirtiéndose en la fuente de riesgo y por ende en el objeto de las prácticas que se tomen para la gestión de este, es decir, a la fuente de peligro se le debe dominar o mantener a una distancia segura (Morrison, 2009, p. 19); el estudio del delito se hace desde un análisis pragmático en el que no hay lugar para la reflexión, como decisión racional y autónoma del individuo en el que la sociedad se manifiesta como víctima y sobre el estado no recae ninguna responsabilidad, pues es el sujeto quien decidió actuar de determinada manera existiendo la posibilidad de actuar conforme al consenso, entonces no es solamente la política pública la que se estudia desde el marco de la publicchoice, sino también el delito desde el análisis del economicchoice, esto es evaluar el coste del daño ocasionado por el imputado y no estableciendo metas retributivas ni preventivas(Serrano Maillo, 2003, p. 263).

En este sentido, pretende anticipar dificultades, interesándose no en el delito per se, sino en su posibilidad, preocupándose en la gestión antes que en la reforma ya que su objetivo no radica en eliminar el delito sino en minimizar el riesgo (Benero, 2009, p. 150), para ello su estrategia principal se basa en la exclusión, esto porque al tratarse de una visión economicista, se basa en las estadísticas y probabilidades que proporcionan una forma de visualizar la población en categorías y subpoblaciones según criterios de riesgo (Rivera Beiras, 2005, p. 236), y a partir de ello definir el grupo que puede ser una eventual amenaza a la seguridad, sin embargo no solo clasifica a la población como sujetos-riesgo, sino que determina la población sujeto-víctima y sobre la cual debe recaer la protección que se decida; en este sentido la criminología actuarial procura, desde la administración, brindar herramientas a su selecta comunidad para que se sienta más segura, por ejemplo mediante el ofrecimiento de pólizas de seguro, que solucionan el problema subjetivo referido a la percepción de la seguridad.

Siguiendo ese orden, el objetivo de la justicia será el manejo de grupos poblacionales clasificados e identificados previamente como permanente o puntualmente peligrosos y riesgosos(Rivera Beiras, 2005) y la censura sobre un individuo se hará con fundamento a su pertenencia al grupo clasificado como tal y la aplicación de una pena no tendrá fundamento en la resocialización, sino en la separación de la comunidad entendida como una unidad.

Por ello, los grupos excluidos obedecen igualmente a las lógicas del mercado, es decir que puede señalarse en primera medida que los pobres son entendidos como la nueva clase peligrosa (Rivera Beiras, 2005, p. 240), pues la criminología actuarial no se cuestiona la desigualdad social, sino que hace uso de ella para determinar el grupo poblacional a excluir; así mismo se racionaliza el uso del espacio y se organiza a la comunidad de tal manera que los eventuales riesgos se encuentren controlados y alejados del sujeto-víctima, en esto cumple una función fundamental la prisión, ya que es el método empleado para mantener bajo control a los individuos señalados como enemigos a través del consenso social, es decir, su función se encuentra encaminada a la eliminación del sujeto del contexto social. Se identifica entre la masa de desviados, a la limitada porción de delincuentes irrecuperables para los cánones de conformidad, los teóricos de la incapacitación selectiva proponen adoptar medidas tendencialmente definitivas respecto a los sujetos cuyos comportamientos desviados tan solo pueden ser contrarrestados mediante el internamiento (De Giorgi, 2000, p. 57).

Bajo tales criterios, se cuestiona qué estatus de legitimidad tiene los discursos de las relaciones internacionales y la criminología (Morrison, 2009, p. 39) cuando los controles a quienes cometen violaciones de derechos humanos, se activan solamente cuando poderosos que los cometieron dejan de serlo, esto es, virtualmente, cuando 
“pierden la guerra"(Aniyar, 2010, p. 60).

La riqueza y el poder siempre han mantenido relaciones incestuosas: la riqueza es utilizada para adquirir poder político y viceversa, el poder es un medio de adquirir riquezas, por ello la influencia en la conducción de la política, lo que no es una buena noticia para que se haga justicia a los más pobres(Geneviève, 2009, p. 31).

Sobre la base de todo lo anteriormente planteado se afirma que es evidente un discurso contradictorio de la integración regional y mundial, a través de instrumentos legales y políticos, marcado por las desigualdades estatales y de poder entre los estados, pues por un lado los medios masivos acuden a los conceptos universalistas acerca del derecho internacional, los derechos humanos y las apelaciones a los juicios morales y por otra parte las demandas pragmáticas de ejercer el poder de un mundo de Estado-Nación (Morrison, 2009, p. 7), tienen un refuerzo adicional en la organización geográfica existente en el mundo, pues como se señaló, se pretende una supuesta integración para reforzar la unidad y fortalecer la división social y la aceptación de la exclusión de los grupos no pertenecientes a la unidad.

Entonces, el derecho penal entendido como derecho de garantías a través del cual pretenda resolverse un conflicto en el cual se han afectado bienes jurídicos de ciertos sujetos y manteniendo como límite el respeto inherente que recae sobre quienes entran al proceso penal como acusados, debe propugnarse como un elemento con el cual se pretenda lograr determinada igualdad en el diálogo entre las partes (Bustos Rámirez \& Larrauri, 1993, p. 40).

La Corte Penal Internacional, instituida como máximo mecanismo de protección de los derechos humanos de la sociedad, se presenta ante la comunidad por un lado como la garantía de quienes puedan ser atacados en su integridad y por otro lado, como el mecanismo represor a través del cual se ejerce una función de prevención general sobre los asociados para que entren a hacer parte del sistema penal internacional; sin embargo, los fines altruistas y protectores de derechos humanos se desdibujan cuando el órgano internacional se encuentra al imperio de un mercado, en el que hoy la globalización se presenta en una forma no siempre sutil de totalitarismo, pues es esta el factor de nuevas criminalidades, pues los carteles internacionales del crimen y la delincuencia de cuello blanco se han visto facilitados por el fin de la denominada guerra fría (Aniyar, 2010, p. 66-67).

Por lo cual, frente a las graves violaciones de derechos humanos que se presentan en el mundo, los millones de víctimas que deja la estructura económica impuesta por la globalización y la participación de los actores económicos, resaltando la participación del Estado en la violencia estructural ya que el poder económico se encuentra ligado al poder político, que ejerce represiones a través de las cuales se limita el desarrollo material e intelectual de segmentos de la sociedad(Morrison, 2009, p. XLVI), la criminología contemporánea ha realizado un llamado a reducir el enfoque que hasta la actualidad permanece en los estudios criminológicos y en el delito local, pues como se observa la aplicación de la criminología actuarial segrega, discrimina y selecciona a la población, y por el contrario se debe enfocar el análisis sobre los crímenes de masa contra la humanidad- las agresiones a los derechos humanos y a los bienes comunes realizados por los Estados y por los mercados(Fejarrioli, 2013, p. 3).

Se propone una criminología que además de encontrarse dirigida a la protección de los derechos humanos, tenga como objeto la criminalidad del poder revertir las connotaciones racistas que han marcado y siguen marcando la criminología (Fejarrioli, 2013, p. 4), no se trata de visibilizar la violencia estructural, sino de enfrentar, académica y políticamente, la incesante repetición(Tombs, 2013, p. 285), que la ha hecho visible y la ha puesto a la opinión como una actuación que debe ser aceptada, porque por su repetición es considerada normal.

Una criminología de los derechos humanos se encuentra legitimada por la constatación de que hay de formas de macrociminalidad y que como se ha señalado no han sido estudiadas por la criminología (Aniyar, 2010, p.126,127), acudiendo al reiterado llamado de la interdisciplinariedad y la autonomía de la criminología frente al derecho penal, abandonando su carácter auxiliar para fortalecerse y fundamentar un análisis que a la postre conlleve a la determinación de criterios político criminales materializados en el establecimiento de una política pública internacional a través de la cual se investiguen los delitos que dejan millones de víctimas hoy en el mundo y que permanecen ocultos o simplemente aceptados. 
Por ello, se reconoce que el establecimiento de la justicia global a través de la $\mathrm{CPI}$, es un avance democrático y como señala Ferrajoli (2013) en sí mismo, se trata de la invitación a la criminología de ampliar su espectro, sin embargo se considera una institución que no solo por su corta edad presenta debilidades, sino por la interferencia política que persiste sobre ella, impidiéndole actuar independiente, imparcial y autónomamente, por lo que desde la criminología lo que debe ocurrir, como se ha indicado, es un cambio de su objeto de estudio, dirigiéndose a los sujetos activos y poderosos(Morrison, 2009, p. 56), y no a su tradicional objeto analizado, individuos de clase baja, previamente seleccionados y a quienes se les recluye como mecanismo de muerte social.

Si bien el análisis presentado pretende que se persigan las conductas corporativas de acuerdo a los delitos ya consagrados en Estatuto, bajo la denominada complicidad empresarial, hay quienes dirigen su mirada además a la persecución de los delitos de sistema que aún no se encuentran tipificados pero que igualmente causan un alto número de víctimas, tales como la restricción del comercio de productos farmacéuticos, la hambruna o el acceso al sistema de salud, se trata entonces de buscar la reversión de la doble vía que hace hoy a la justicia penal una justicia fuertemente clasista: derecho penal máximo, máximamente duro e inflexible contra la delincuencia de los pobres, delincuencia de subsistencia; derecho penal mínimo, máximamente leve e indulgente contra los crímenes del poder, la corrupción y las bancarrotas, incluyendo la agresión y la violencia de la policía contra los manifestantes (Ferrajoli, 2013), no se pretende construir un derecho penal solo con fachada de eficiente sino se pretende que ante los problemas que se presentan en la actualidad y ante los cuales el derecho penal aparece como inútil, se protejan y garanticen derechos humanos, a través de la persecución de las conductas descritas en las que los poderes económicos favorecen y contribuyen a los llamados delitos a gran escala y sobre los cuales debe dirigirse la mirada de los criminólogos de hoy.

\section{REFERENCIAS BIBLIOGRÁFICAS}

Acosta, A. ( 2013). La brecha socioeconómica. Colombia: El pais de las desigualdades, 4.

Aniyar, L. (2010). Criminología de los Derechos
Humanos. Buenos Aires, Argentina: Editores del Purto.

Arango, R. (2005). El concepto de Derechos Sociales Fundamentales. Colombia: Legis Editores S.A.

Benero, M. (2009). El nuevo paradigma de la exclusión social para el conocimiento criminológico. Derecho y Ciencias Sociales, 149-159.

Blanco, G. (1999). Volver a pensar la educación. In: Congreso internacional de Didáctica, Política, Educación y Sociedad. Madrid: Morata.

Bodenheimer, E. (2005). Teoria del Derecho. México: Fondo de cultura económica.

Bustos Rámirez, J., \& Larrauri, E. (1993). Victimología: Presente y Futuro. Bogotá, Colombia: Temis.

CEDE (UNIANDES); IGAC; Universidad de Antioquia. (2012.). Atlas de la distribución de la Propiedad Rural en Colombia. Medellin: Cede.

CEDE. (2005). Medicion del impacto de un programa de reforma agraria en Colombia. Clectivo Antigona, 2.

Centro de Integración, Cooperación y Desarrollo Internacional(s.f.). Cooperación Internacional. Recuperado de CICODI: http://www.cicodi.org/Publicaciones/CDocuments andSettingscarmenEscritoriopublicacionesenviar Bienvenida-21570664250.pdf

CEPAL. (2002). Globalización y Desarrrollo. Brasilia.

Correa Henao, N. R. (2011). La constitución para todos. Bogotá: Grupo Editorial Ibañez.

CP. (1991). Constitución Política de Colombia. Bogotá: Presidencia de la República.

De Giorgi, A. (2000). Tolerancia Cero. Estrategias y prácticas de la sociedad de control. Roma, Italia: DeriveApprodi.

Durkheim, E. (2009). Educación y sociología. Madrid: Popular.

Ferrajoli, L. (2013). Criminología, crímenes globales y derecho penal: El debate epistemológico en la criminología contemporánea. Revista Crítica Penal y Poder,(4), 
$1-11$.

Fiscalía vs. Callixte Mbarushimana. Decisión sobre la confirmación de cargos, ICC-01/04-01/10-465-Red (Corte Penal Internacional. SCP I 16 de diciembre de 2011).

Fiscalía vs. Germain Katanga y Mathieu Ngudjolo Chui, ICC-01/04-01/07-3319-tENG/FRA (Corte Penal Internacional. SCP II 21 de diciembre de 2012).

Furió, M. E. (2009). Organización y administración administrativa -Plan de estudios. Universidad Nacional de Salta, Facultad de humanidades. Escuela de ciencias de la educación.

Geneviève, J. (2009). Resistencias contra la impunidad de los crímenes económicos. (Y. U. Vidal, Trad.) Santiago de Chile, Chile: Lom Ediciones.

Gutiérrez Pascual, V. (2000). La acción educativa. En: Sanches, A.H. Manual de Sociología (págs. 205-226). Valladolid: España.

Huergo, J. (2005). Los medios y tecnologías Educación. La Plata: Universidad Nacional de La Plata.

Huertas Diaz, O., \& otros. (2008). Manual pedagógico para la formación en derechos humanos. Bogotá: Ibañez.

Huertas, O. (2013). Política criminal del Estado colombiano y los derechos de las personas privadas de la libertad: Análisis legislativo y jurisdicional Corte Constitucional. Revista Logos Ciencia y Tecnología, 53.

Ibáñez Gonzalez , J. (2007). Derecho a la Educación y Ciudadanía Democrática. El derecho a la educación como desarrollo constitucional del pensamiento republicano cívico. Bogotá: Editorial Ibáñez.

INCODER, I. C. (2005). Zonificacion Agroecolóogica, Evaluacion económica y organización socioempresarial de sistema de producción prioritarios en el área de desarrollo rural del sur del Atlántico. Bogota: Convenio PNUD - CORPOICA.

Informe Nacional de Desarrollo Humano. (2011). Colombia rural, razones para la esperanza, 2011. Bogotá.
IGAC. (2012). Atlas de la distribución de la propiedad rural en Colombia . Bogotá: Imprenta Nacional de Colombia.

Jiménez, J. (2012). Agenda de incidencia para el desarrollo Rural del Atlantico formuladas por las organizaciones de 6 municipios que son acompañados por el PDP como insumo para el area de desarrolo rural.

Kiss, A. ( 2013). La contribución en la comisión de un crimen por un grupo de personas en la jurisprudencia de la Corte Penal Internaciona. InDret, 1-34.

Kymlicka, W. (2003). La Política Vernácula, Nacionalismo, multiculturalismo y ciudadanía. Barcelona: Paidós.

Lamo de Espinos, E. (1998). Diccionario de sociología. Madrid: Alianza Editorial.

Ley 30. (1992). Ley de Educación. Bogotá: Presidencia de la República.

Machado, A. (2005). Tenencia de tierras, problema agrario y conflicto. Bogota: Facultad de Ciencias Económicas de la Universidad Nacional de Colombia.

Ministerio de Agricultura y Desarrollo Rural. (2006). Colombia: Un pais de oportunidades para la inversion forestal. Bogota: Diseño e Impresión papel y Plástico y impresores.

Morrison, W. (2009). Criminología, civilización y nuevo orden mundial. Barcelona, España: Antrophos.

Naciones Unidas. (1998). Resolución A/52/13.

Olivera, A. (2008). Ciudadania y Demogracia. Mexico D.F: Instituto Federal Electoral.

Programa de las Naciones Unidas para el Desarrollo (s.f.). Principio 2. Recuperado de PNUD: http://www.pnud.org.co/img_upload/6565656565 6561656565656535383538/Principio\%202\%20La s\%20empresas $\% 20$ deben $\% 20$ asegurarse $\% 20$ de $\% 20$ que $\% 2$ sus $\% 20$ empresas $\% 20$ no $\% 20$ son $\% 20$ complices\%20en\%20la\%20vulnerabilidad\%20de \%20los\%20derechos\%20humanos.pdf.

República de Colombia. (2011). Constitución Política de Colombia 1991. Bogotá: Leyer.

República de Colombia. Departamento Nacional de Planeación, Consejo Nacional de Política 
Económica y Social. (2013). Documento COMPES 162. Bogotá.

Rico, H. R. (2013). Administracion Pública, Modernizacion del Estado. Barranquilla: Editorial Mejoras.

Rivera Beiras, I. (2005). Política criminal y sistema penal: viejas y nuevas racionalidades punitivas. Bacelona, España: Anthropos.

Rivera, V. A. (2007). La tenencia de la tierra: un problema en Colombia.

Roth Deubel, A.N. (2007). Teorías y Marcos de Análisis para las Políticas Públicas. In:Fundamentos de Políticas Públicas. Bogotá: Universidad Nacional de Colombia.

Sánchez, F. (2007). Conflictos de tierras, derechos de propiedad y el surgimiento de la economía exportadora en el siglo XIX en Colombia. Documento cede, 2007-19.

Santos, B. d., \& García Villegas, M. (2001). El caleidoscopio de las justicias en Colombia. Bogotá: Slglo del Hombre Editores - Universidad de Los Andes.

Sarramona, J. (2000). Teoría de la Educación. Barcelona: Ariel.
Sentencia T-781 (Corte Constitucional 30 de Septiembre de 2010).

Serrano Maillo, A. (2003). Introducción a la Criminología. Madrid: Dykindon.

Shuterland, E. (1999). El delito de cuello blanco. Madrd, España: Ediciones de La Piqueta.

Sozzo, M. (2000). Seguridad Urbana y Tácticas de Prevención del Delito. Cuadernos de Jurisprudencia y Doctrina Penal,

Tapia, L. (2008). Política Salvaje. La Paz (Bolivia): Muela del diablo editores.

Tombs, S. (2013). Trabajando para el mercado "libre": complicidad estatal en la rutina del daño corporativo en el Reino Unido. Revista Crítica Penal y Poder, 5, 266-290.

Villegas, M. ( 2012). Periodico Diario Empresarial La República.

Weber, M. (1944). Economía y Sociedad. México D.F.: Fondo de Cultura Económica.

Zemelman, H. (2010). Pensamiento crítico y neoliberalismo en América Latina. Conferencia Universidad Pedagógica Nacional. Bogotá: Universidad Pedagógica Nacional. 